NASA/TM-2010-216072

AIAA-2009-1458

\title{
Envelope Protection for In-Flight Ice Contamination
}

David R. Gingras and Billy P. Barnhart

Bihrle Applied Research Inc., Hampton, Virginia

Richard J. Ranaudo

University of Tennessee Space Institute, Tullahoma, Tennessee

Thomas P. Ratvasky

Glenn Research Center, Cleveland, Ohio

Eugene A. Morelli

Langley Research Center, Hampton, Virginia 


\section{NASA STI Program . . . in Profile}

Since its founding, NASA has been dedicated to the advancement of aeronautics and space science. The NASA Scientific and Technical Information (STI) program plays a key part in helping NASA maintain this important role.

The NASA STI Program operates under the auspices of the Agency Chief Information Officer. It collects, organizes, provides for archiving, and disseminates NASA's STI. The NASA STI program provides access to the NASA Aeronautics and Space Database and its public interface, the NASA Technical Reports Server, thus providing one of the largest collections of aeronautical and space science STI in the world. Results are published in both non-NASA channels and by NASA in the NASA STI Report Series, which includes the following report types:

- TECHNICAL PUBLICATION. Reports of completed research or a major significant phase of research that present the results of NASA programs and include extensive data or theoretical analysis. Includes compilations of significant scientific and technical data and information deemed to be of continuing reference value. NASA counterpart of peer-reviewed formal professional papers but has less stringent limitations on manuscript length and extent of graphic presentations.

- TECHNICAL MEMORANDUM. Scientific and technical findings that are preliminary or of specialized interest, e.g., quick release reports, working papers, and bibliographies that contain minimal annotation. Does not contain extensive analysis.

- CONTRACTOR REPORT. Scientific and technical findings by NASA-sponsored contractors and grantees.
- CONFERENCE PUBLICATION. Collected papers from scientific and technical conferences, symposia, seminars, or other meetings sponsored or cosponsored by NASA.

- SPECIAL PUBLICATION. Scientific, technical, or historical information from NASA programs, projects, and missions, often concerned with subjects having substantial public interest.

- TECHNICAL TRANSLATION. Englishlanguage translations of foreign scientific and technical material pertinent to NASA's mission.

Specialized services also include creating custom thesauri, building customized databases, organizing and publishing research results.

For more information about the NASA STI program, see the following:

- Access the NASA STI program home page at http://www.sti.nasa.gov

- E-mail your question via the Internet to help@ sti.nasa.gov

- Fax your question to the NASA STI Help Desk at 443-757-5803

- Telephone the NASA STI Help Desk at 443-757-5802

- Write to: NASA Center for AeroSpace Information (CASI) 7115 Standard Drive Hanover, MD 21076-1320 
NASA/TM-2010-216072

AIAA-2009-1458

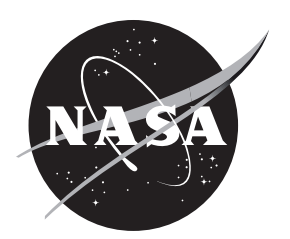

\section{Envelope Protection for In-Flight Ice Contamination}

David R. Gingras and Billy P. Barnhart

Bihrle Applied Research Inc., Hampton, Virginia

Richard J. Ranaudo

University of Tennessee Space Institute, Tullahoma, Tennessee

Thomas P. Ratvasky

Glenn Research Center, Cleveland, Ohio

Eugene A. Morelli

Langley Research Center, Hampton, Virginia

Prepared for the

47th Aerospace Sciences Meeting

sponsored by the American Institute of Aeronautics and Astronautics

Orlando, Florida, January 5-8, 2009

National Aeronautics and

Space Administration

Glenn Research Center

Cleveland, Ohio 44135 


\section{Acknowledgments}

The authors would like to thank the NASA Aviation Safety Program's

Integrated Vehicle Health Management Project for their sponsorship of the effort reported herein.

Trade names and trademarks are used in this report for identification only. Their usage does not constitute an official endorsement, either expressed or implied, by the National Aeronautics and Space Administration.

Level of Review: This material has been technically reviewed by technical management.

Available from

NASA Center for Aerospace Information 7115 Standard Drive

Hanover, MD 21076-1320
National Technical Information Service 5285 Port Royal Road Springfield, VA 22161 


\title{
Envelope Protection for In-Flight Ice Contamination
}

\author{
David R. Gingras and Billy P. Barnhart \\ Bihrle Applied Research Inc. \\ Hampton, Virginia 23666 \\ Richard J. Ranaudo \\ University of Tennessee Space Institute \\ Tullahoma, Tennessee 37388 \\ Thomas P. Ratvasky \\ National Aeronautics and Space Administration \\ Glenn Research Center \\ Cleveland, Ohio 44135 \\ Eugene A. Morelli \\ National Aeronautics and Space Administration \\ Langley Research Center \\ Hampton, Virginia 23681-2199
}

\begin{abstract}
Fatal loss-of-control (LOC) accidents have been directly related to in-flight airframe icing. The prototype system presented in this paper directly addresses the need for real-time onboard envelope protection in icing conditions. The combinations of a-priori information and real-time aerodynamic estimations are shown to provide sufficient input for determining safe limits of the flight envelope during in-flight icing encounters. The Icing Contamination Envelope Protection (ICEPro) system has been designed and implemented to identify degradations in airplane performance and flying qualities resulting from ice contamination and provide safe flight-envelope cues to the pilot. Components of ICEPro are described and results from preliminary tests are presented.
\end{abstract}

\section{Nomenclature}

$\begin{array}{ll}A & \text { stability matrix } \\ B & \text { control matrix } \\ b & \text { reference span } \\ \bar{c} & \text { mean aerodynamic chord } \\ C_{l_{\beta}} & \text { rolling moment due to sideslip angle derivative, } \partial C_{l} / \partial \beta \\ C_{l_{\delta a}} & \text { rolling moment due to aileron deflection derivative, } \partial C_{l} / \partial \delta_{a} \\ C_{l_{\delta r}} & \text { rolling moment due to rudder deflection derivative, } \partial C_{l} / \partial \delta_{r} \\ C_{l_{p}} & \text { rolling moment due to nondimensional roll rate derivative, } \partial C_{l} / \partial(p b / 2 V) \\ C_{l_{\mathrm{r}}} & \text { rolling moment due to nondimensional yaw rate derivative, } \partial C_{l} / \partial(r b / 2 V) \\ C_{m_{\alpha}} & \text { pitching moment due to angle of attack derivative, } \partial C_{m} / \partial \alpha \\ C_{m_{\delta e}} & \text { pitching moment due to elevator deflection derivative, } \partial C_{m} / \partial \delta_{e} \\ C_{m_{q}} & \text { pitching moment due to nondimensional pitch rate derivative, } \partial C_{m} / \partial(q \bar{c} / 2 \mathrm{~V})\end{array}$




$\begin{array}{ll}C_{N_{\alpha}} & \text { normal force due to angle of attack derivative, } \partial C_{N} / \partial \alpha \\ C_{N_{\delta e}} & \text { normal force due to elevator deflection derivative, } \partial C_{N} / \partial \delta_{e} \\ C_{N_{q}} & \text { normal force due to nondimensional pitch rate derivative, } \partial C_{N} / \partial(q \bar{c} / 2 \mathrm{~V}) \\ C_{n_{\beta}} & \text { yawing moment due to sideslip angle derivative, } \partial C_{n} / \partial \beta \\ C_{n_{\delta a}} & \text { yawing moment due to aileron deflection derivative, } \partial C_{n} / \partial \delta_{a} \\ C_{n_{\delta r}} & \text { yawing moment due to rudder deflection derivative, } \partial C_{n} / \partial \delta_{r} \\ C_{n_{p}} & \text { yawing moment due to nondimensional roll rate derivative, } \partial C_{n} / \partial(p b / 2 V) \\ C_{n_{r}} & \text { yawing moment due to nondimensional yaw rate derivative, } \partial C_{n} / \partial(r b / 2 V) \\ C_{Y_{\beta}} & \text { side force due to sideslip angle derivative, } \partial C_{Y} / \partial \beta \\ C_{Y_{\delta a}} & \text { side force due to aileron deflection derivative, } \partial C_{Y} / \partial \delta_{a} \\ C_{Y_{\delta r}} & \text { side force due to rudder deflection derivative, } \partial C_{Y} / \partial \delta r \\ C_{Y_{p}} & \text { side force due to nondimensional roll rate derivative, } \partial C_{Y} / \partial(p b / 2 V) \\ C_{Y_{r}} & \text { side force due to nondimensional yaw rate derivative, } \partial C_{Y} / \partial(r b / 2 V) \\ I S P & \text { Icing Severity Parameter } \\ J & \text { cost function } \\ L S E & \text { least-squared error } \\ R M S & \text { root-mean square } \\ t & \text { time } \\ U & \text { Theil coefficient } \\ u & \text { control vector } \\ \hat{u} & \text { control vector predicted from inversion routine } \\ V & \text { true velocity, ft/s } \\ y, \hat{y} & \text { measured and predicted output } \\ x & \text { state vector } \\ \omega & \text { frequency, rad/s } \\ \theta & \text { parameter vector } \\ & \end{array}$

\section{Introduction}

The University of Tennessee Space Institute (UTSI) in partnership with Bihrle Applied Research (BAR) is conducting a three-year cooperative research effort with NASA in response to the NASA Research Announcement (NRA) NNH06ZEA001N under Appendix B of the Aviation Safety Program. This research is being performed to develop an Icing Contamination Envelope Protection (ICEPro) system that meets the objectives defined under the Integrated Vehicle Health Management (IVHM) Project, topic IVHM 3.1, Environmental Hazards, which are caused by the "Effects of Icing on Aircraft State". This paper presents the results of the first year and a half of research, which focuses on the concept, design, and development of a real-time vehicle state assessment system.

\section{Background}

Airframe icing continues to be a threat to aviation safety across the globe. Icing-induced loss of control incidents and accidents have occurred and continue to occur on all classes of aircraft-from 
general aviation airplanes (Ref. 1) and business jets (Ref. 2), to transport category aircraft (Refs.3 to 8). NASA recently published results from statistical analyses that examined trends of icing-related events over a 16-year period (1988 to 2003) (Ref. 9). The study showed that nearly 9-percent of all fatal accidents from Part 121 and Scheduled Part 135 operations occurred while flying in icing conditions. During an icing encounter, flight characteristics can be severely degraded if hazardous ice formations accrete on wings and tail surfaces due to improper use of the ice protection systems (IPS), IPS failure, or encountering "exceedence conditions". Exceedence conditions occur when an aircraft is exposed to icing rates outside of the FAR 25 Appendix C criteria, for which the aircraft is certificated; Super-cooled Large Droplet (SLD) icing is one example. Each of these situations has caused serious aircraft handling problems and resulted in stall and/or departure from controlled flight.

One notable accident referenced above involved an ATR 72 that flew through SLD icing conditions near Roselawn, Indiana on October 31, 1994. Even with the IPS operating normally, the aircraft experienced a roll control anomaly that led to the loss of control and impact into the ground. This accident and others since then have led to numerous safety recommendations from the National Transportation Safety Board (NTSB) (Refs. 10 and 11) and the Commercial Aviation Safety Team (CAST) (Ref. 12) and motivated research activities within NASA and the FAA. One NASA sponsored activity called the Smart Icing Systems was led by the University of Illinois, Urbana-Champaign (UIUC). The Smart Icing Systems took a systems level approach to detecting icing conditions, operating ice protection systems and alerting the flight crew to the status of the aircraft (Ref. 13).

This work laid the foundation to continue research to develop and improve real-time state assessment methods for vehicle health management with application to detecting and mitigating icing hazards. This is now being pursued through a NASA Research Announcement with the University of Tennessee Space Institute and Bihrle Applied Research, Inc., in collaboration with NASA Glenn and NASA Langley Research Centers. The development of real-time state assessment methods and their use in defining flight and control limits on pilot displays are an essential aspect of this research effort. The eventual fusing of these methods with real-time or near real-time icing weather information will not only assist the pilot with the aircraft control task, but will further improve situational awareness and decision-making capability. This capability will allow pilots to continue safe flight while planning an icing escape strategy.

The following sections of this paper provide details of the design, implementation, and verification process of this unique system.

\section{ICEPro Concept}

The ICEPro concept is best summarized by the hypothesis posed by the development team during preliminary stages of the design process.

By the real-time processing of measured state and control information, estimates of stability and control can be used in conjunction with a knowledge base, comprised of a-priori data, to provide pilots with envelope-limiting cueing in order to avoid loss-of-control or adverse conditions resulting from in-flight icing.

Perhaps the best place to begin the discussion of the system concept is to answer the question "How will the flight envelope be protected?” The ICEPro concept relies on the actions of a proficient pilot responding to appropriate cueing and information on the primary and secondary displays in the cockpit. It is believed that with these cues, both visual and aural, the pilot can make informed decisions as to how the airplane is being flown.

With this assumption, the question can be asked "What cues should be provided to the pilot?" The ICEPro concept provides envelope protection by issuing advisories, cautions, and warnings in indications of airspeed limits, angle of attack limits, flap position limits, and control effectiveness status. The indications are intended to be consistent with typical advisories and warnings that appear on typical 
displays such that they are intuitive and effective. Figure 1 provides an example of the cueing that is used in the system.

\section{Airspeed Cues}

Airspeed carats provide predicted values for high and low airspeed limits for the current aircraft configuration and predicted icing condition.

\section{Angle of Attack Brackets}

Angle of attack brackets provide maneuvering limits in pitch for the pilot. These limits are defined by a predicted stall angle of attack for the current configuration of the vehicle and contamination state, and the minimum safe angle of attack that is set to prevent tail stall or negative-g protection.

\section{Flap Position}

One of the most dangerous flight regimes for operation with ice is on approach. Often, deploying flaps in icing conditions can lead to severe degradations in stability and control. As a result, ICEPro provides a flap position indication that advises the pilot as to the state of the vehicle at the current flap deflection. As flaps are deployed during icing conditions, if the system detects degradations in stability and control, the indicator will change to an amber color, cautioning further deployment of the flaps. As the condition worsens, the indicator turns red, warning the pilot of the danger, advising him to stop deployment and retract the flaps until the condition is cleared.

\section{Stability and Control}

Stability and control indicators are provided to inform the pilot of an adverse change in the stability and or control in the pitch, roll, or yaw axes. These indications on the Primary Flight Display (PFD) are accompanied by indications on the Engine Indication and Crew Alerting System (EICAS) display showing flight control status display of control effectiveness and status, as well as detailed messaging.

\section{Climb Limiting}

A performance- based cue to provide the pilot an indication of climb potential given the current state of the aircraft, is a Climb Limit caution and warning. This indicator will provide the pilot with indication that the single-engine climb potential for the current flap setting has degraded below $100 \mathrm{ft}$ per minute.

To generate effective and reliable cueing, quite a bit of work is required behind the scenes to assess and predict the limits of the flight envelope. These predictions and assessments are carried out by making use of three key components: the knowledge base, state estimation, and system logic.

The knowledge-base contains a-priori information about the subject aircraft in its uncontaminated, or "clean," state as well as information describing the vehicle in its "worst-case" contaminated state. Next, components are designed to use measured data from the aircraft to estimate the current aerodynamic state, and detect changes. The most challenging part of the system development is the executive module, a component which uses the current state information and compares it with information extracted from the knowledge base to provide valid envelope protection cueing to the pilot.

The sections below provide details of the system design and implementation, and the system evaluation process to be performed in the coming year. 


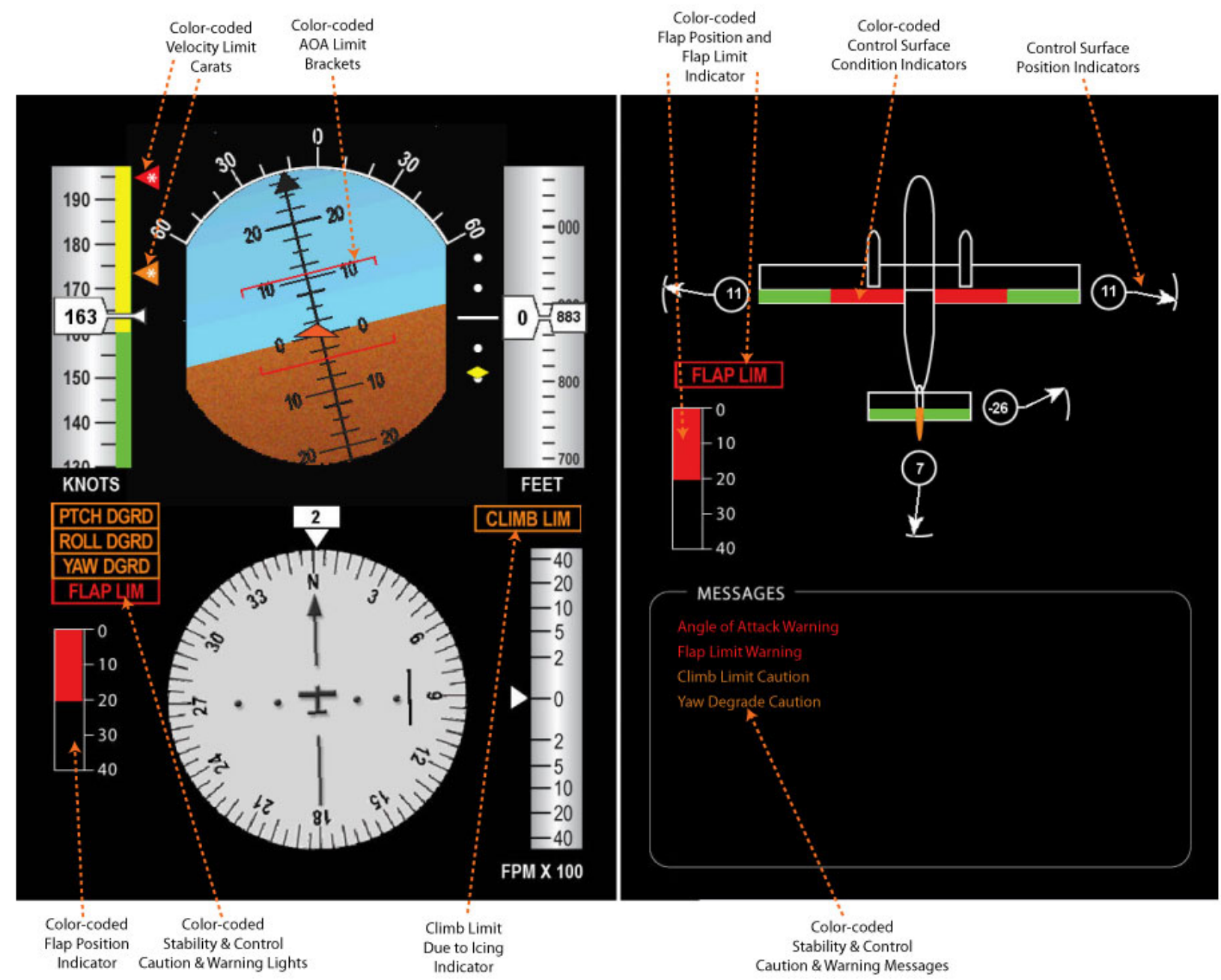

Figure 1.-ICEPro Envelope Protection Cues on the Primary Flight Display (left) and Flight Control Status Page (right)

\section{System Design}

The design of the system is based on three modes of operation: a MONITOR mode that provides initial detection of in-flight icing, an ID mode that provide a diagnosis of the condition, and a REPORTING mode, providing the prognosis of the condition and mitigation through cueing. Figure 2 presents a simplified flow diagram of the system modes and states. Details, such as latching and delatching logic and specific logic for driving each of the caution/warning messages have been omitted to reduce the complexity of the diagram.

\section{Monitor Mode}

The purpose of the MONITOR mode is to provide the initial indication that the real time aircraft state has degraded from a nominal baseline condition. It is designed to passively monitor the aerodynamic state of the aircraft in two ways. Because drag rise is an early indication that ice contamination is present, the first parameter monitored is the drag of the vehicle, which is accomplished through comparisons of airspeed measurements and predictions of aircraft performance for the given conditions and configuration. For the second evaluation, a novel approach to assessing the stability and control of the airplane is used in parallel with the drag monitoring. This technique, the Dynamics Inversion Control Evaluation System (D-ICES) makes use of the system knowledge base to predict the control deflections 


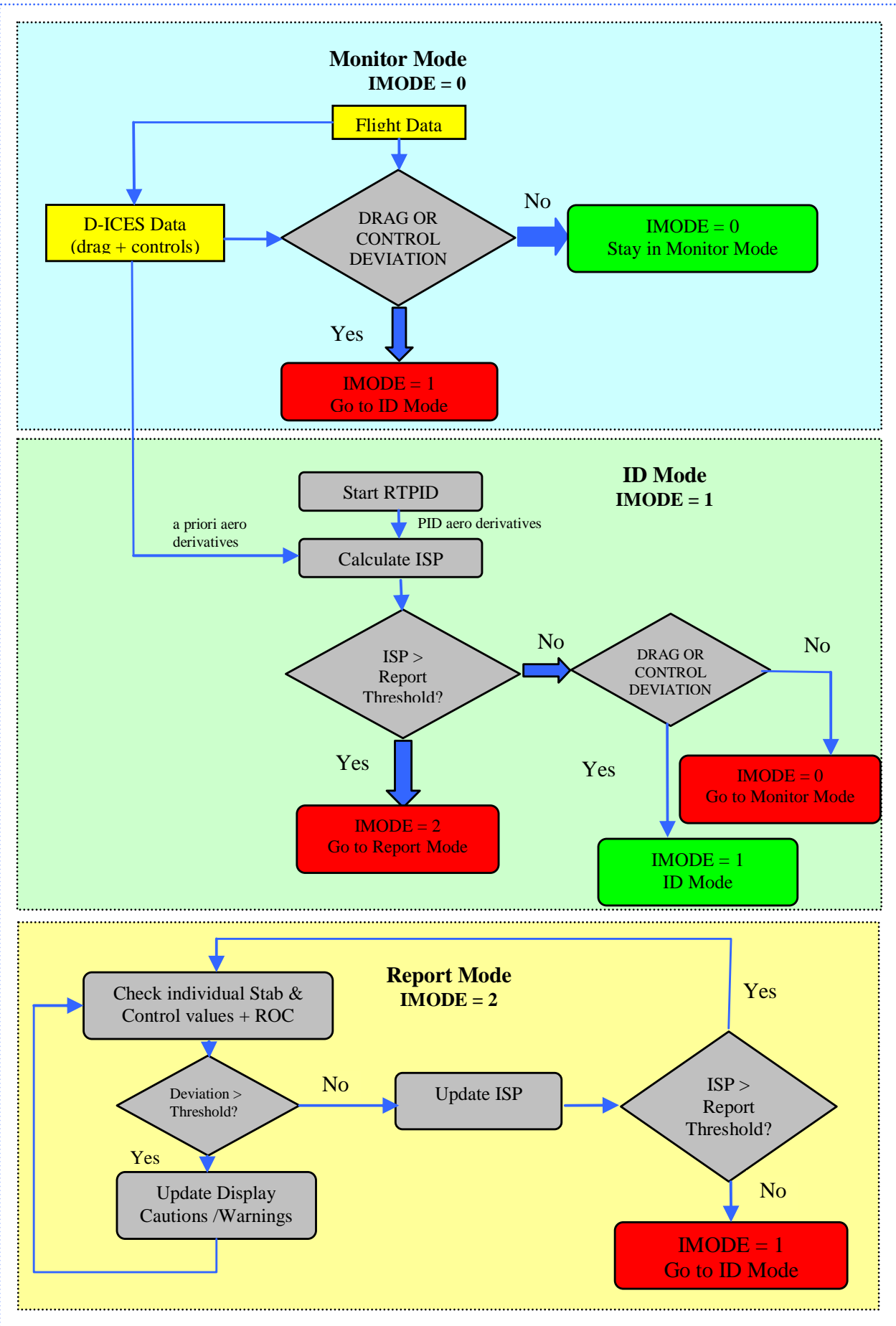

Figure 2.-Simplified ICEPro system state diagram. 


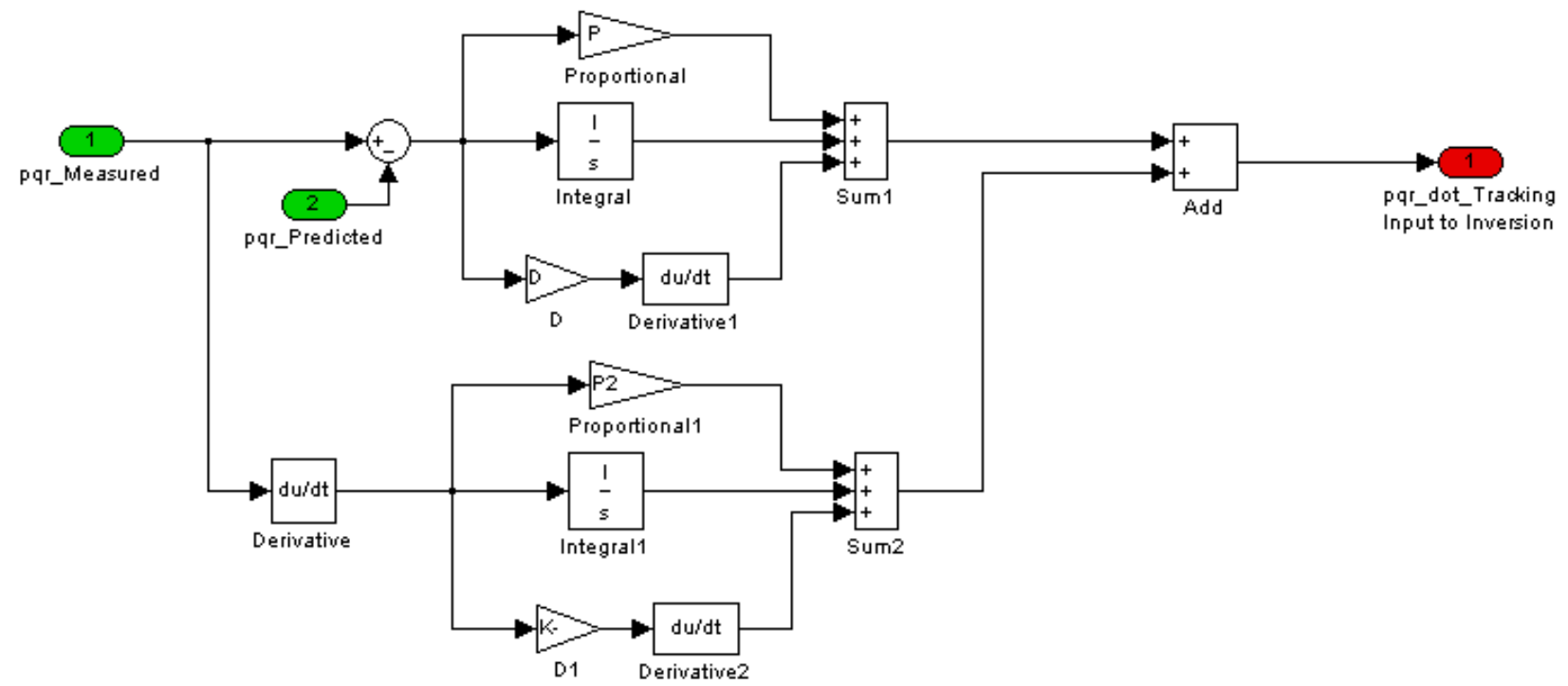

Figure 3.--Tracking algorithm for acceleration signal input to the dynamic inversion scheme.

necessary to achieve the vehicle motion. D-ICES tracks the current pitch, roll, and yaw rate in each axis using a proportional, integral, and derivative (PID) control with lead compensation (Figure 3). With this tracking, the amount of angular acceleration required to match the aircraft motion is determined. Using information from the knowledge base, predictions of the current "clean" stability of the vehicle are entered into the aircraft equations of motion along with weight and balance information and the tracking accelerations to compute a "residual" acceleration vector.

By assuming this residual acceleration is a direct result of control movement, a prediction of control deflections can be obtained (Eq. (1)). Changes in the vehicle aerodynamic state from the "clean" can be detected by tracking these predictions of the control deflection in flight and comparing them to actual control deflections.

$$
\begin{aligned}
& \dot{x}_{\text {Measured }}=A x_{\text {Predicted }}+B u_{\text {Predicted }} \\
& \hat{u}_{\text {Predicted }}=B_{\text {Control }}{ }^{-1}\left[\dot{x}_{\text {Measured }}-A_{\text {Stability }} x_{\text {Predicted }}\right]
\end{aligned}
$$

The actual comparisons in the logic are based on the calculated Theil coefficients for velocity and elevator deflections. The Theil coefficients are used in a moving time window to evaluate how well the extracted data is matching the expected levels during that time period. These statistics form the basis for the Icing Severity Parameter to be discussed later in the paper. The form of the Theil coefficients is shown in Equation (2).

$$
U=\frac{\sqrt{\frac{1}{N} \sum_{N}^{1}(y-\hat{y})^{2}}}{\sqrt{\frac{1}{N} \sum_{N}^{1} y^{2}}+\sqrt{\frac{1}{N} \sum_{N}^{1} \hat{y}^{2}}}=\frac{L S E}{\sum R M S}
$$

Combining the detection of control requirement change and the drag build-up prediction, preliminary indications of icing can be assumed when the Theil coefficients for these parameters exceed a threshold level that has been determined through simulated exercise of the system. This preliminary detection results in a system state switch to the ID mode. 


\section{ID Mode}

In the ID mode, estimates of the vehicle's current aerodynamic state are computed by invoking realtime parameter identification (RTPID). The RTPID algorithm being employed was developed by Morelli (Ref. 14), and is based on a frequency domain approach implemented in version 2.0 of System IDentification Programs for AirCraft (SIDPAC) (Refs. 15 and 16).

The approach uses a linearized model of the vehicle dynamics, Equation (3), where $A, B, C$, and $D$ are matrices containing stability and control derivatives.

$$
\begin{aligned}
& \dot{x}(t)=A x(t)+B u(t) \quad x(0)=x_{O} \\
& y(t)=C x(t)+D u(t)
\end{aligned}
$$

Time-varying estimates of the stability and control derivatives are determined using measured airplane control surface deflections and measured states from air data, angular rates, and attitude. Outputs are rotational and translational accelerations. To determine the estimates, a cost function is formulated in the frequency domain from the Fourier transform of the model in Equation (3),

$$
\begin{aligned}
& j \omega \tilde{x}(\omega)=A \tilde{x}(\omega)+B \tilde{u}(\omega) \\
& \tilde{y}(\omega)=C \tilde{x}(\omega)+D \tilde{u}(\omega)
\end{aligned}
$$

The cost function is

$$
J_{k}=\frac{1}{2} \sum_{n=1}^{m}\left|j \omega_{n} \tilde{x}_{k}(n)-a_{k} \tilde{x}(n)-b_{k} \tilde{u}(n)\right|^{2} \text { for } m \text { frequencies }
$$

where $a_{k}$ and $a_{k}$ are the $k$ th row of matrices $A$ and $B$, respectively, and $\tilde{x}_{k}(n) \equiv \tilde{x}_{k}\left(\omega_{n}\right), \tilde{u}_{k}(n) \equiv \tilde{u}_{k}\left(\omega_{n}\right)$. Each line in Equation (4) can be analyzed separately in this way, which implements an equation-error formulation (Ref. 14). The least squares cost function in each case can be formulated as

$$
J=\frac{1}{2}(Y-X \theta)^{\dagger}(Y-X \theta)
$$

where $^{\dagger}$ indicates complex conjugate transpose,

$$
Y=\left[\begin{array}{c}
j \omega_{1} \tilde{x}_{k}(1) \\
\vdots \\
j \omega_{m} \tilde{x}_{k}(m)
\end{array}\right] \quad X=\left[\begin{array}{cc}
\tilde{x}^{T}(1) & \tilde{u}^{T}(1) \\
\vdots & \vdots \\
\tilde{x}^{T}(m) & \tilde{u}^{T}(m)
\end{array}\right]
$$

and the unknown parameters from $A$ and $B$ are contained in the parameter vector $\theta$. The least squares parameter vector estimate is obtained as the value of $\theta$ that minimizes the cost function in Equation (6) (Ref. 14), 


$$
\begin{aligned}
& \hat{\theta}=\left[\operatorname{Re}\left(X^{\dagger} X\right)\right]^{-1} \operatorname{Re}\left(X^{\dagger} Y\right) \\
& \operatorname{cov}(\hat{\theta}) \equiv E\left[(\hat{\theta}-\theta)(\hat{\theta}-\theta)^{T}\right]=\hat{\sigma}^{2}\left[\operatorname{Re}\left(X^{\dagger} X\right)\right]^{-1} \\
& \hat{\sigma}^{2}=\frac{1}{m}(Y-X \hat{\theta})^{\dagger}(Y-X \hat{\theta})
\end{aligned}
$$

Performing the identification in the frequency domain is advantageous for this application because of computational efficiency, robustness to noise and data dropouts, and reliable confidence bounds from the covariance matrix. To ensure reliable estimates, the ICEPro features a self checking algorithm that examines the confidence bound of the parameter estimates. Table 1 lists the parameters that are being identified in real-time.

TABLE 1.-AERODYNAMIC PARAMETERS IDENTIFIED BY RTPID

\begin{tabular}{|c|c|c|}
\hline$C_{N_{\alpha}}$ & $C_{Y_{\delta a}}$ & $C_{l_{p}}$ \\
\hline$C_{N_{\delta e}}$ & $C_{Y_{\delta r}}$ & $C_{l_{r}}$ \\
\hline$C_{N_{q}}$ & $C_{Y_{p}}$ & $C_{n_{\beta}}$ \\
\hline$C_{m_{\alpha}}$ & $C_{Y_{r}}$ & $C_{n_{\delta a}}$ \\
\hline$C_{m_{\delta e}}$ & $C_{l_{\beta}}$ & $C_{n_{\delta r}}$ \\
\hline$C_{m_{q}}$ & $C_{l_{\delta a}}$ & $C_{n_{p}}$ \\
\hline$C_{Y_{\beta}}$ & $C_{l_{\delta r}}$ & $C_{n_{r}}$ \\
\hline
\end{tabular}

If confidence of the estimated parameters falls below acceptable levels due to lack of data information content, an automated excitation of the aircraft control surfaces is triggered to improve data information content. This interface with the subject vehicle is performed as though an autopilot is driving control deflections using multi-frequency orthogonal inputs (Fig. 4) (Ref. 17). Amplitudes of the inputs are adjusted to provide excitation while minimizing vehicle motion.
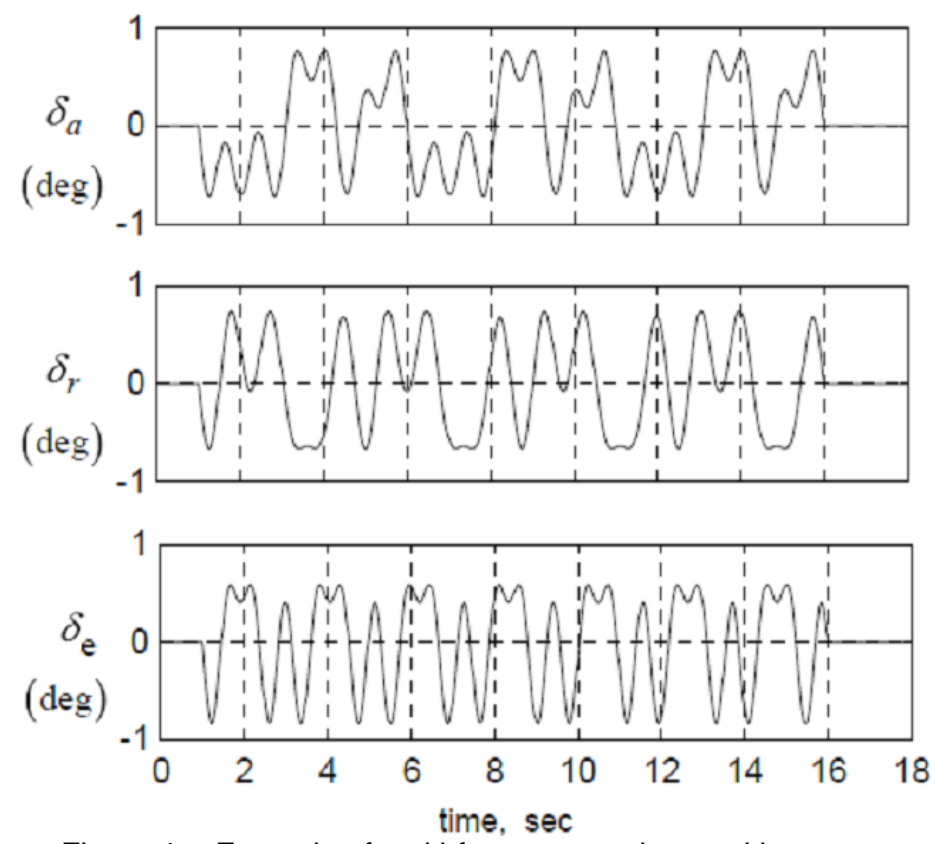

Figure 4.-Example of multi-frequency orthogonal inputs. 
Once reliable estimates of the aerodynamics state (stability and control derivatives) are obtained, comparisons of this estimated state are made with knowledge-base predictions of the "clean" vehicle aerodynamics and "worse-case" vehicle aerodynamics. These comparisons are performed to establish an Icing Severity Parameter (ISP). The ISP varies from 0 to 1, where 0 indicates a "clean" configuration with no ice, and 1 indicating the worst case ice condition that is modeled in the system aerodynamics model. The level of the ISP triggers the next mode switch to Report mode and is used for several of the envelope protection predictions. The general form of the ISP calculation is the sum of the differences between the RTPID aerodynamic derivatives estimates and the knowledge base expected clean airplane values divided by the differences between the knowledge base iced and clean values, as shown in Equation (9). The terms used for the ISP calculation are those that show a significant enough difference due to icing. Terms with small icing effects are not included.

$$
I S P=\frac{\sum_{i=1}^{n}\left[\frac{\left(\text { Value }_{\text {expected }}-\text { Value }_{\text {actual }}\right)_{i}}{\left(\text { Value }_{\text {expected }}-\text { Value }_{\text {iced }}\right)_{i}}\right]}{n}
$$

\section{Report Mode}

Given the predicted ISP, while in reporting mode, the knowledge-base provides predictions of stall angle, minimum and maximum safe speeds for operation, as well as predictions of climb capability. It is these important pieces of information that drive the pilot cueing for envelope protection. Furthermore, comparison of the current estimates of aerodynamic parameters from the RTPID with clean predictions from the knowledge base provides measures of changes in stability margin, dynamic stability, and control effectiveness. When parameters exceed a predetermined threshold, advisories, cautions and warnings are issued accordingly to help the pilot keep the aircraft within a safe operating envelope.

\section{System Implementation}

The initial implementation of the ICEPro system is being performed on a DeHavilland DHC-6 Twin Otter, a high wing twin turboprop aircraft. This selection was made for several reasons. First, NASA Glenn Research Center has operated a modified Twin Otter as an icing research aircraft for over 25 years and has accumulated substantial data records of performance and stability and control effects due to icing. Secondly, NASA and BAR have developed simulation models of this aircraft in both clean and iced configurations to develop a concept demonstrator for including icing effects in initial and recurrent pilot training (Refs. 18 and 19). These data bases were extensively validated against flight data to insure that they accurately represent the baseline un-iced Twin Otter, as well as the iced airplane (Ref. 20). This effort resulted in the Ice Contamination Effects Flight Training Device (ICEFTD) (Fig. 5), a portable flight training device that has been used in a number of workshops and seminars to demonstrate the undesirable effects of icing on flight characteristics (Refs. 21 and 22).The ICEFTD will be used in this current effort for pilot evaluations of the ICEPro system. The third reason for selecting the Twin Otter for the initial ICEPro implementation is the potential to migrate the system to the NASA Twin Otter Icing Research Aircraft for final demonstration of the system in real world conditions.

The ICEPro system was developed and deployed in Bihrle Applied Research's D-Six PC-Based simulation environment. All of the ICEPro functions, including the software for driving the flight displays are provided in a single computer that runs the software in real time. The system can be interfaced with the ICEFTD device or mounted in the NASA Twin Otter for flight demonstrations. A functional diagram of the ICEPro system is shown in Figure 6. The system consists of Data Acquisition and Executive functions which control the various modules that make up the system. 


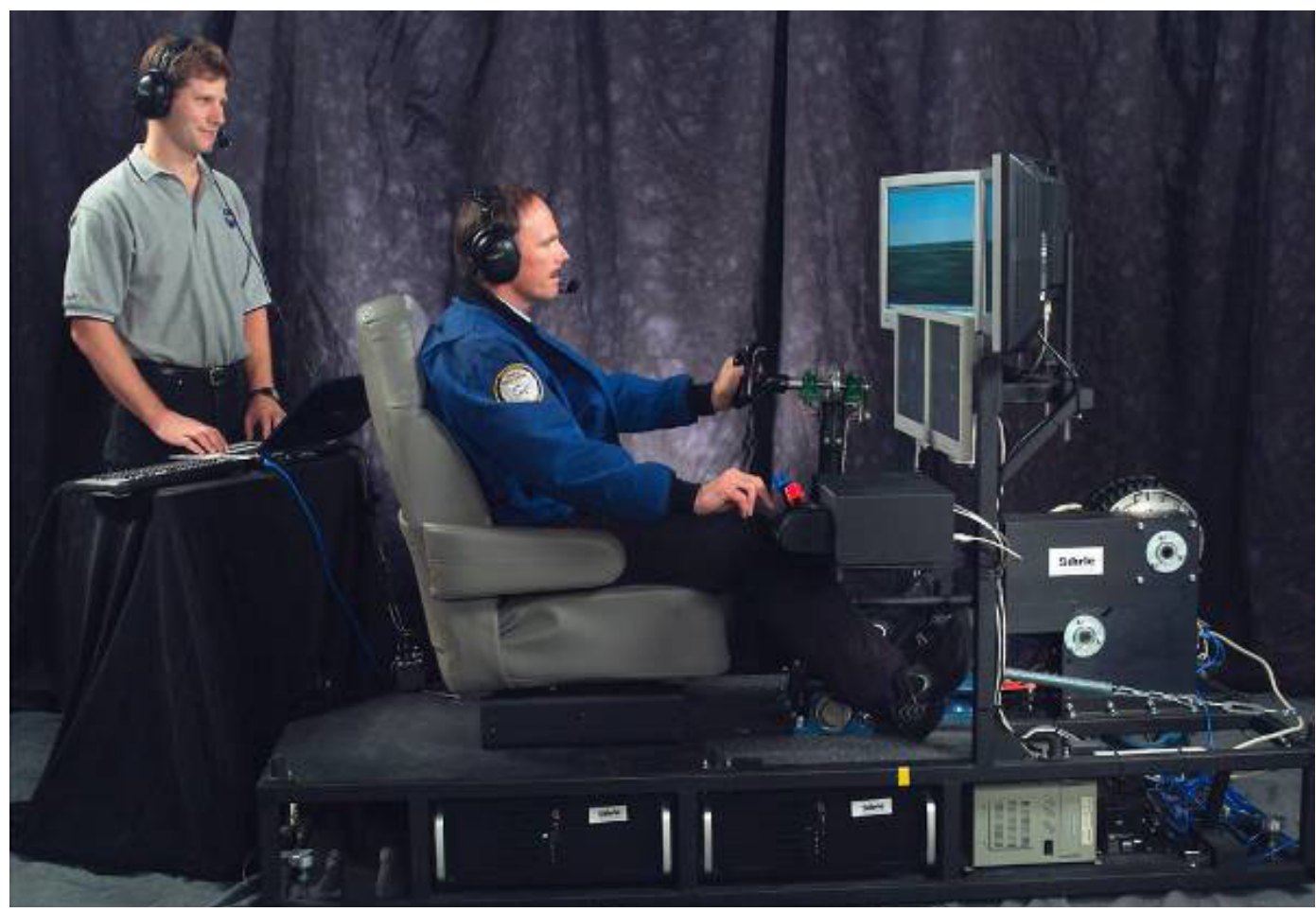

Figure 5.-NASA's Ice Contamination Effects Flight Training Device (ICEFTD).

INTERNAL (DSIX) PROCESSES

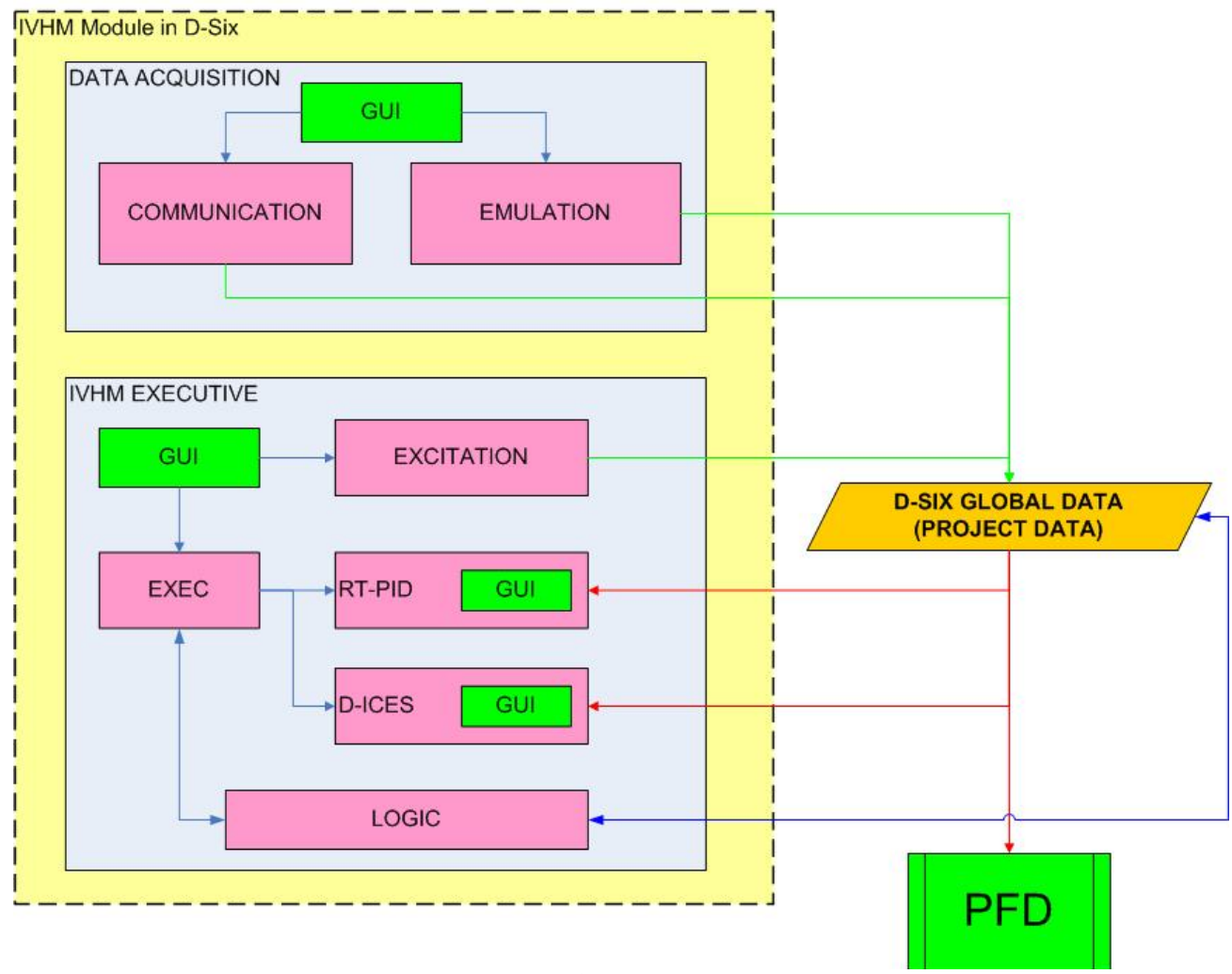

Figure 6.-ICEPro System Design Functions. 
The data acquisition portion receives data from the data bus on the airplane or from an emulation of the airplane data system if it is working with the simulator and not the airplane. It then makes the appropriate data available to the various other modules for processing and to the cockpit displays. The Executive portion provides all of the logic and calculation modules required to determine the icing state and what cues should be provided to the pilot.

\section{Knowledge Base}

All of the development effort has been done using the simulation of the Twin Otter as the aircraft. The knowledge base used by ICEPro is also a copy of the nonlinear data bases used in the simulation. The D-ICES algorithms were populated with data from the Twin Otter physics simulation. Although the system model and the physics model in the simulation contain identical data, the models are treated separately. The perfect a priori knowledge of the physics allows development of system logic and debugging.

\section{D-ICES}

As mentioned above, the ICEPro D-ICES system model was populated using data from the physics model of the Twin Otter. Using these data, the inversion control surface predictions and stability and control predictions matched the simulation perfectly. This arrangement, allowed for systematic tests to be performed on the system algorithms as well as system threshold settings.

The D-ICES algorithm was implemented as a C/C++ code module into the D-Six Simulation environment running at $50 \mathrm{~Hz}$. Figure 7 present examples of the D-ICES output for a no-ice and an iced condition.
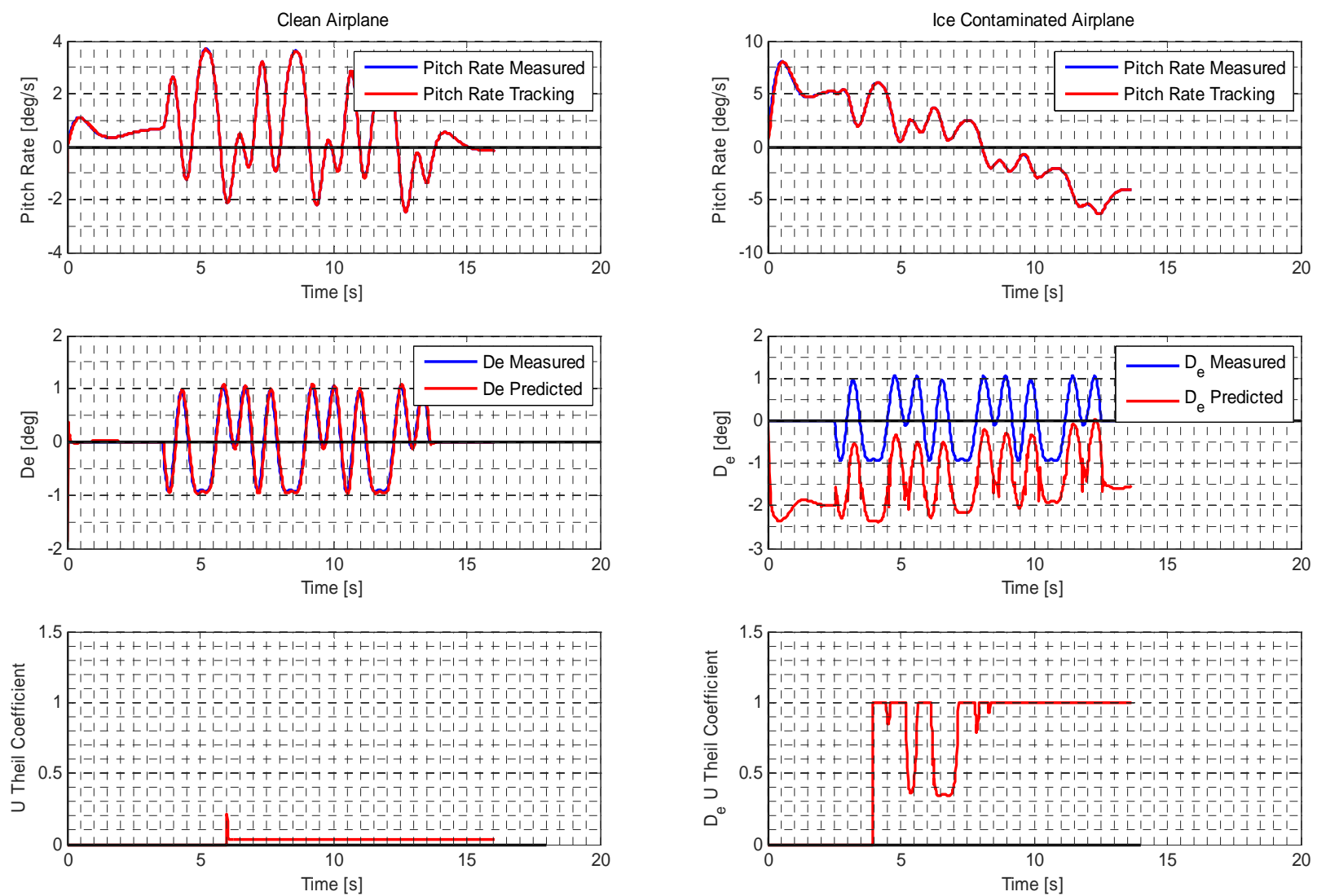

Figure 7.-D-ICES output for a no-ice and an iced condition. 

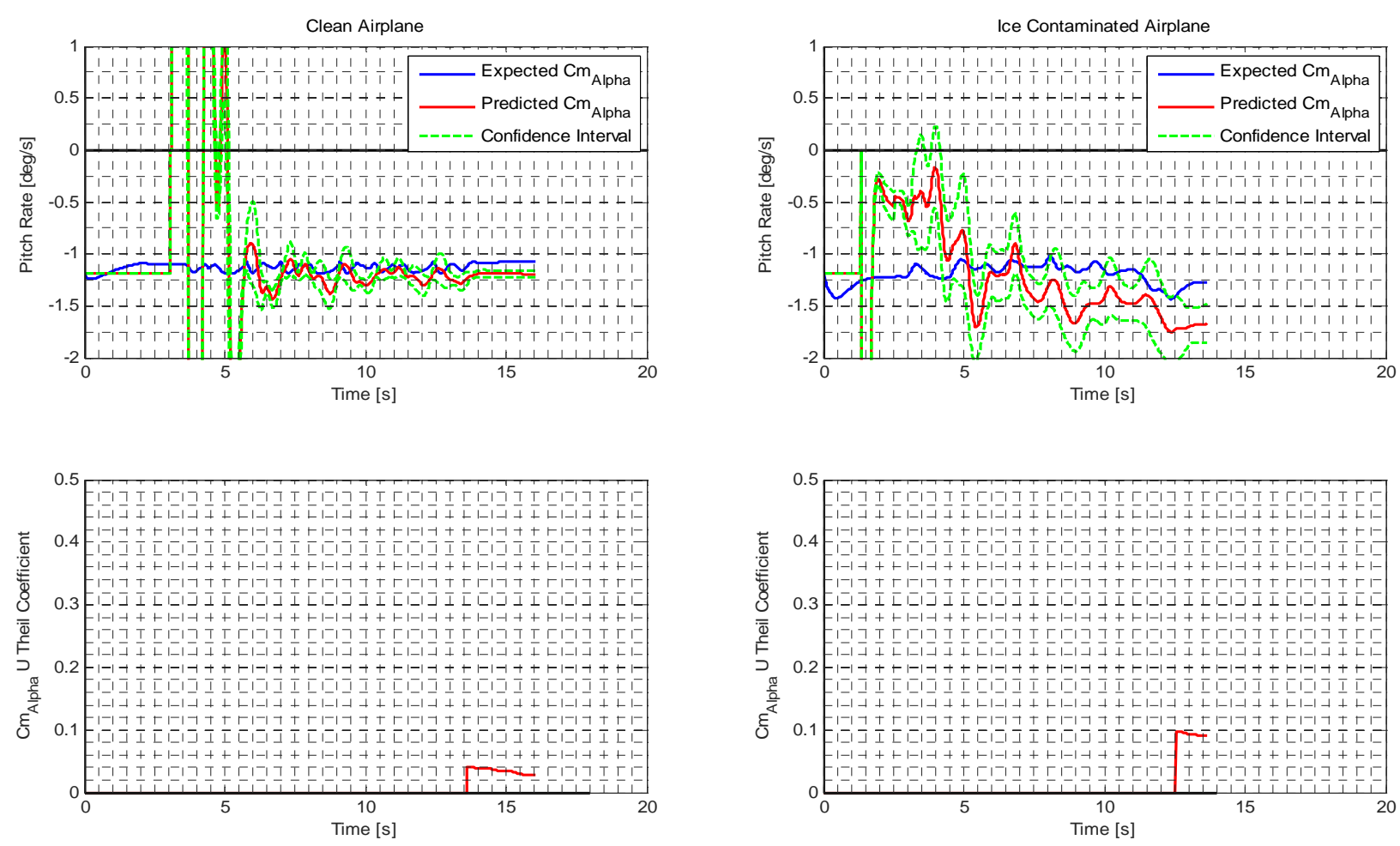

Figure 8.-RTPID results from the ICEPro system.

\section{RTPID}

Since the real-time PID algorithms are natively coded in the SIDPAC MATLAB scripts, these scripts were used in the ICEPro system with little modification. A D-Six plug-in module was written to create an instance of a MATLAB engine. During simulation execution, the D-Six system loop made calls to the MATLAB engine to provide input data, execute RTPID functions, and retrieve results. This model also was executed at a $50 \mathrm{~Hz}$ frame rate. Figure 8 presents examples of typical RTPID results from the systems and shows the increase in the Theil inequality coefficient for the comparisons with two different situations.

\section{Logic Details}

The implementation of the logic tree was designed to allow researchers to easily modify system thresholds and parameters during testing and evaluation of the system. This was done through the use of an initialization text file that is loaded at a press of a button on the system GUI. Amongst the parameters available for system tuning are, data buffering times, latching and delatching times between modes, thresholds for tracking, and latching times for cautions and warnings.

\section{Future Effort: ICEPro System Evaluation}

Testing and evaluation of the ICEPro system will be accomplished to verify its functionality and to assess its utility in simulated icing scenarios, using the NASA Ice Contamination Effects Flight Training Device (ICEFTD). Functionality evaluations will be performed initially by UTSI and NASA personnel, and will focus on verification that the system performs as intended. Initial testing will also involve a pretest screening of ICEPro in UTSI's simulation laboratory to identify and correct any system anomalies before final integration with the ICEFTD. A test plan has been written, which defines eight test 
procedures that will facilitate an evaluation of alert thresholds, cue implementation, messaging, display characteristics, and absence of nuisance alerts. The performance metrics in the test plan are based upon meeting certain airworthiness criteria from applicable paragraphs of Federal Aviation Regulations (FAR) Part 23 (Ref. 23) and the related icing Advisory Circular (AC) 23.1419-2D. The initial functionality evaluation will be assessed by performing the following test procedures as recommended in that AC:

- Stalling speeds and maneuver margin with critical "normal” ice accretions_-1g wings level stall condition

- Turning flight and accelerated turning stalls

- Climb-One Engine Inoperative (Normal, Utility, and Acrobatic) for aircraft that weigh more than $6000 \mathrm{lb}$

- Approach and landing with failure shape ice accretions

- $\quad$ og pushover maneuvers

- Lateral-directional static stability

- Static longitudinal stability

- Dynamic longitudinal and lateral directional stability

Once the initial functionality evaluation is successfully completed, further testing will be performed to evaluate the utility of ICEPro by two sample groups of ten pilots or more. These sample groups will be randomly selected from industry and government flight test organizations because the nature and objectives of this test favor those familiar with development and certification flight testing. One group of pilots will be a control group, who will fly the test scenario without the benefit of envelope protection cues, and the second group will be an experimental group who will fly the scenario with envelope protection cueing of ICEPro. The test scenario will be based on the subject pilots flying a flight planned route during which icing is encountered. The ICEFTD will be programmed to "accrete ice" at a given rate as the pilot flies the required route, and must then safely maneuver for approach and landing. Both quantitative and qualitative data will be acquired during these tests. Quantitative data will include time histories of flight path maintenance, pilot control activity, and other performance parameters such as airspeed, angle of attack (AOA), and configuration management. Qualitative data will include pilot task assessments of workload using appropriate rating methodologies such as the NASA Task Load Index (TLX) (Ref. 24) or Cooper-Harper handling qualities rating scale (Ref. 25). Upon completion of testing, pilots will complete a Likert scale (Ref. 26) survey questionnaire that will solicit their opinions on cueing design and implementation, aircraft state awareness, flight safety, and perceived task performance. Quantitative data will be reduced to evaluate pilot error based on defined performance metrics related to the flight task. Qualitative data will be reduced to assess workload and pilot opinion. Data from the two groups will be then compared using descriptive and inferential statistical methods to determine how well the ICEPro system has met its design objectives.

\section{Operational Utility Assessment in a Simulated Real Time Icing Weather Condition}

Archived icing weather data has been obtained from the National Center for Atmospheric Research (NCAR), which will be integrated with the ICEFTD and presented to the pilot on a separate map-type flight display. These data represent a known hazardous icing condition, which occurred on January 27, 2004, in the Cleveland, Ohio area for a 3-hr period of time, and are in an ASCII format. The horizontal resolution is $5 \mathrm{~km}$, and the vertical resolution is from 1000 to 12,000 ft. Notional cockpit displays of this weather condition have been designed, but are not finalized. The integration of these data with cockpit displays and ICEPro will support a realistic icing encounter simulation for pilot evaluations. Here, pilot in the loop participation will involve a single sample group of ten pilots or more, who represent a cross section of regional airline pilots. The test plan will provide a scenario, which will focus on the pilot's use of simulated real-time weather data and envelope protection cueing to mitigate a potentially hazardous icing encounter. Quantitative data will consist of flight track time histories and altitude changes to record 
the pilot's tactical decisions. Qualitative data will be acquired in the form of a post-ICEPro test opinion survey to assess situation and state awareness, and the overall utility of the fully-integrated, real-time weather and envelope protection system. The results of these two pilot-in-the-loop simulations are expected to verify and validate the concepts originally proposed in meeting the expected outcomes of the NASA Research Announcement (NRA) Research Opportunities in Aeronautics (ROA-2006), NNH06ZNH001, topic 3.1, environmental hazards.

\section{Conclusion}

In keeping with the NASA goal to improve the safety of commercial and general aviation aircraft, an envelope protection system was developed using no direct ice detection devices. Through the use of measured data, a priori information, and real-time stability and control estimates, this system computes an icing severity parameter. This parameter is used to trigger appropriate pilot cueing to warn the pilot of hazardous conditions and provide guidance for action to mitigate the situation. The main advantage of the system is that it uses data that are readily available in modern avionics systems and once adjusted to specific aircraft makes and models, and mated to modern display systems, should provide sufficient pilot cueing for envelope protection against icing related incidents.

At the time of writing, all subsystems, D-ICES and RTPID algorithms have undergone unit-level checks and have been verified. In addition, logic paths have been tested and verified. Currently, the system is undergoing comprehensive preliminary testing and adjustment. Final results are expected by the second quarter of 2009.

\section{References}

1. National Transportation Safety Board, Factual Report on Cessna CE-208 Caravan Accident on Oct. 21, 2001 at Dillingham, AL, NTSB ID DCA02MA003.

2. National Transportation Safety Board, Crash During Approach to Landing, Circuit City Stores, Inc., Cessna Citation 560, N500AT, Pueblo, Colorado, Feb. 16, 2005, Aircraft Accident Report NTSB/AAR-07/02. Washington, D.C., Jan. 2007.

3. National Transportation Safety Board, In-Flight Icing Encounter And Loss Of Control, Simmons Airlines, D.B.A. American Eagle Flight 4184 Avions De Transport Regional (ATR) Model 72-212, N401am Roselawn, IN, Oct. 31,1994, NTSB Aircraft Accident Report, NTSB/AAR-96/01, Washington, DC., Jul. 1996.

4. National Transportation Safety Board, In-Flight Icing Encounter And Uncontrolled Collision With Terrain; Comair Flight 3272; Embraer Emb-120rt, N265ca; Monroe, MI, Jan. 9, 1997, NTSB Aircraft Accident Report, NTSB/AAR-98/04, Washington D.C., Nov. 1998.

5. Transportation Safety Board of Canada, Loss of Control on Go-around (Rejected Landing), Air Canada Canadair CL-600-2B19 C-FSKI, Fredericton Airport, New Brunswick, Report Number A97H0011, Dec. 1997.

6. Aviation Safety Council, GE791 Occurrence Investigation Report, In-Flight Icing Encounter and Crash into the Sea Transasia Airways Flight 791, ATR72-200, B-22708, 17 Kilometers Southwest of Makung City, Penghu Islands, Taiwan, Dec. 21, 2002, ASC-AOR-05-04-001, Taipei, Taiwan.

7. Inflight Loss of Control due to Airframe Icing Saab 340B, VH-OLM, 28 Jun. 2002, Australian Transport Safety Bureau AIR SAFETY INVESTIGATION BO/2002030704, Dec. 2003.

8. "Roll Oscillations on Landing, Air Canada, Airbus 321-211, C-GJVX and C-CIUF, Toronto/Lester B. Pearson International Airport, Ontario, 07 Dec. 2002,” Transportation Safety Board of Canada Aviation Investigation Report A02O0406.

9. Jones, S. M., Reveley, M.S., Evans, J.K., Barrientos, F.A., Subsonic Aircraft Safety Icing Study, NASA/TM-2008-215107, Jan. 2008.

10. National Transportation Safety Board, Safety Recommendation to Mitigate the Existing Risk to the Cessna 208 Fleet during the Current Icing Season. A-06-01 through -03, Jan. 17, 2006. 
11. National Transportation Safety Board, Safety Recommendation to Mitigate the Existing Risk to the Saab 340 Fleet When Operating in Icing Conditions. A-06-48/51, Jul. 10, 2006.

12. Russell, P., Pardee, J., "Joint Safety Analysis Team-CAST Approved Final Report Loss of Control JSAT Results and Analysis,” Dec. 2000.

13. Bragg, M.B., Basar, T., Perkins, W.R., Selig, M.S., Voulgaris, P.G., Melody, J.W., Sarter, N.B., Smart Icing Systems for Aircraft Icing Safety, AIAA-2002-0813, Jan. 2002.

14. Morelli, E.A., "Real-Time Parameter Estimation in the Frequency Domain,” Journal of Guidance, Control, and Dynamics, Vol. 23, No. 5, Sep.-Oct. 2000, pp. 812-818.

15. Morelli, E.A., "System IDentification Programs for AirCraft (SIDPAC)," AIAA-2002-4704.

16. Klein, V and Morelli, E.A., Aircraft System Identification Theory and Practice, American Institute for Aeronautics and Astronautics Inc., Reston, VA, 2006.

17. Morelli, E.A., "Real-time Dynamics Modeling-Data Information Requirements and Flight Test Results,” AIAA-2008-6501.

18. Gingras, D.R, Dickes, E.G, Ratvasky, T.P., and Barnhart, B.P, "Modeling of In-Flight Icing Effects for Pilot Training,” AIAA Modeling and Simulation Technologies Conference and Exhibit, Aug. 5-8, 2002, Monterey, CA, AIAA-2002-4605.

19. Barnhart, B., Dickes, E., Gingras, D., Ratvasky, T., "Simulation Model Development for Icing Effects Flight Training,” SAE 2002-01-1527, Apr. 2002.

20. Ratvasky, T., Blankenship, K., Rieke, W., Brinker, D., "Iced Aircraft Flight Data for Flight Simulator Validation,” SAE-2002-01-1528, Apr. 2002.

21. Ratvasky, T.P, Ranaudo, R.J., Barnhart, B.P., Dickes, E.G, and Gingras, D.R, "Development and Utility of a Piloted Flight Simulator for Icing Effects Training," AIAA 41st Aerospace Sciences Meeting and Exhibit, Jan. 6-9, 2003, Reno, NV, AIAA-2003-0022

22. Barnhart, Billy P., and Ratvasky, Thomas P., "Effective Training for Flight in Icing Conditions," NASA/TM-2007-214693, Mar. 2007.

23. Chapter 14, Code of Federal Regulations, Federal Aviation Regulations Part 23, Airworthiness Standards: Normal, Utility, and Acrobatic, and Commuter Category Airplanes, Subpart B, Pub. National Archives and Records Administration, 2008.

24. Hart, S., \& Lowell, S., "Development of NASA-TLX: Results of Empirical and Theoretical Research,” in Hancock, P., and Meshkati, N., (Eds.), Human Mental Workload, North Holland Press, Amsterdam, 1988, pp. 239-250.

25. Cooper, G.E., and Harper, R.P., "The Use of Pilot Rating in the Evaluation of Aircraft Handling Qualities,” NASA TN D-5153, Apr. 1969

26. Articulate Global, Inc. “Likert Scale Questions,” http://www.articulate.com/support/help/quizmaker /v2/content/Likert_Scale_Questions 


\begin{tabular}{|c|c|c|}
\hline \multicolumn{2}{|c|}{ REPORT DOCUMENTATION PAGE } & $\begin{array}{l}\text { Form Approved } \\
\text { OMB No. 0704-0188 }\end{array}$ \\
\hline \multicolumn{3}{|c|}{ 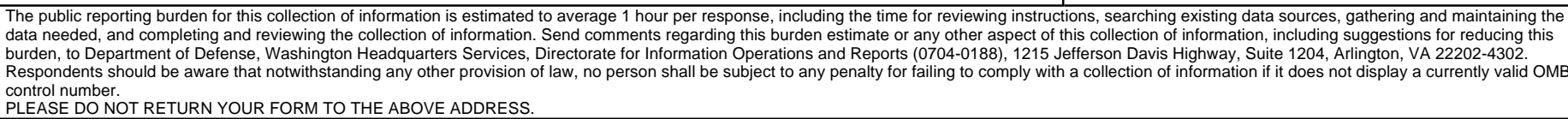 } \\
\hline $\begin{array}{l}\text { 1. REPORT DATE (DD-MM-YYYY) } \\
01-02-2010\end{array}$ & $\begin{array}{l}\text { 2. REPORT TYPE } \\
\text { Technical Memorandum }\end{array}$ & 3. DATES COVERED (From - To) \\
\hline \multirow{3}{*}{\multicolumn{2}{|c|}{$\begin{array}{l}\text { 4. TITLE AND SUBTITLE } \\
\text { Envelope Protection for In-Flight Ice Contamination }\end{array}$}} & 5a. CONTRACT NUMBER \\
\hline & & 5b. GRANT NUMBER \\
\hline & & 5c. PROGRAM ELEMENT NUMBER \\
\hline \multirow{3}{*}{\multicolumn{2}{|c|}{$\begin{array}{l}\text { 6. AUTHOR(S) } \\
\text { Gingras, David, R.; Barnhart, Billy, P.; Ranaudo, Richard, J.; Ratvasky, Thomas, P.; Morelli, } \\
\text { Eugene, A. }\end{array}$}} & 5d. PROJECT NUMBER \\
\hline & & 5e. TASK NUMBER \\
\hline & & $\begin{array}{l}\text { 5f. WORK UNIT NUMBER } \\
\text { WBS 645846.02.07.03.11.02 }\end{array}$ \\
\hline \multicolumn{2}{|c|}{$\begin{array}{l}\text { 7. PERFORMING ORGANIZATION NAME(S) AND ADDRESS(ES) } \\
\text { National Aeronautics and Space Administration } \\
\text { John H. Glenn Research Center at Lewis Field } \\
\text { Cleveland, Ohio 44135-3191 }\end{array}$} & $\begin{array}{l}\text { 8. PERFORMING ORGANIZATION } \\
\text { REPORT NUMBER } \\
\text { E-17120 }\end{array}$ \\
\hline \multirow{2}{*}{\multicolumn{2}{|c|}{$\begin{array}{l}\text { 9. SPONSORING/MONITORING AGENCY NAME(S) AND ADDRESS(ES) } \\
\text { National Aeronautics and Space Administration } \\
\text { Washington, DC 20546-0001 }\end{array}$}} & $\begin{array}{l}\text { 10. SPONSORING/MONITOR'S } \\
\text { ACRONYM(S) } \\
\text { NASA }\end{array}$ \\
\hline & & $\begin{array}{l}\text { 11. SPONSORING/MONITORING } \\
\text { REPORT NUMBER } \\
\text { NASA/TM-2010-216072 }\end{array}$ \\
\hline \multicolumn{3}{|c|}{$\begin{array}{l}\text { 12. DISTRIBUTIONIAVAILABILITY STATEMENT } \\
\text { Unclassified-Unlimited } \\
\text { Subject Categories: } 05 \text { and } 08 \\
\text { Available electronically at http://gltrs.grc.nasa.gov } \\
\text { This publication is available from the NASA Center for AeroSpace Information, 443-757-5802 }\end{array}$} \\
\hline
\end{tabular}

\section{SUPPLEMENTARY NOTES}

\section{ABSTRACT}

Fatal loss-of-control (LOC) accidents have been directly related to in-flight airframe icing. The prototype system presented in this paper directly addresses the need for real-time onboard envelope protection in icing conditions. The combinations of a-priori information and realtime aerodynamic estimations are shown to provide sufficient input for determining safe limits of the flight envelope during in-flight icing encounters. The Icing Contamination Envelope Protection (ICEPro) system has been designed and implemented to identify degradations in airplane performance and flying qualities resulting from ice contamination and provide safe flight-envelope cues to the pilot. Components of ICEPro are described and results from preliminary tests are presented.

\section{SUBJECT TERMS}

Aircraft icing; Flight safety; System identification; Dynamic control; Inverse kinematics; Fault detection

\begin{tabular}{|c|c|c|c|c|c|}
\hline \multicolumn{3}{|c|}{ 16. SECURITY CLASSIFICATION OF: } & \multirow{2}{*}{$\begin{array}{l}\text { 17. LIMITATION OF } \\
\text { ABSTRACT } \\
\text { UU }\end{array}$} & \multirow{2}{*}{$\begin{array}{l}\text { 18. NUMBER } \\
\text { OF } \\
\text { PAGES } \\
22\end{array}$} & \multirow{2}{*}{$\begin{array}{l}\text { 19a. NAME OF RESPONSIBLE PERSON } \\
\text { STI Help Desk (email:help@sti.nasa.gov) } \\
\text { 19b. TELEPHONE NUMBER (include area code) } \\
\text { 443-757-5802 }\end{array}$} \\
\hline $\begin{array}{l}\text { a. REPORT } \\
\text { U }\end{array}$ & $\begin{array}{l}\text { b. ABSTRACT } \\
U\end{array}$ & $\begin{array}{l}\text { c. THIS } \\
\text { PAGE } \\
\text { U }\end{array}$ & & & \\
\hline
\end{tabular}



